\title{
Adrenocortical Carcinoma in Children: A Clinicopathological Analysis of 41 Patients at the Mayo Clinic from 1950 to 2017
}

\author{
Nidhi Gupta ${ }^{a}$ Michael Rivera ${ }^{b}$ Paul Novotny ${ }^{c}$ Vilmarie Rodriguez ${ }^{d}$ \\ Irina Bancos ${ }^{\mathrm{e}}$ Aida Lteif ${ }^{\mathrm{a}}$

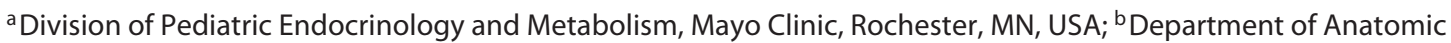 \\ Pathology, Mayo Clinic, Rochester, MN, USA; 'Department of Health Sciences Research, Mayo Clinic, Rochester, MN, \\ USA; ${ }^{d}$ Division of Pediatric Hematology-Oncology, Mayo Clinic, Rochester, MN, USA; ${ }^{\circ}$ Division of Endocrinology, \\ Diabetes, Metabolism and Nutrition, Mayo Clinic, Rochester, MN, USA
}

\section{Keywords}

Adrenal tumor · Child · Adrenalectomy · Mitotane ·

Prognosis

\begin{abstract}
Background/Aims: Adrenocortical carcinoma (ACC) is an aggressive childhood cancer. Limited evidence exists on a definite histopathological criterion to differentiate ACC from adrenocortical adenoma. The aim of this study was to investigate the clinicopathological data of children with ACC, identify prognostic factors, and validate a histopathological criterion to differentiate ACC from adrenocortical adenoma. Methods: This retrospective cohort included 41 children, followed at the Mayo Clinic from 1950 to 2017 (onset of symptoms $\leq 21$ years). Outcomes of interest were: alive with no evidence of disease, alive with evidence of disease, and dead of disease. Results: Median age at onset of symptoms was 15.7 years ( $n=41$; range, $0.2-21$ years). Female:male ratio was 3.6:1. Mixed symptomatology ( $>1$ hormone abnormali-
\end{abstract}

\section{KARGER}

(c) 2018 S. Karger AG, Basel

E-Mail karger@karger.com

www.karger.com/hrp ty) was the most common presentation $(54 \%, n=22)$. Sixtysix percent of patients ( $n=27$ out of 41) underwent total adrenalectomy. Metastatic disease was more common in children aged $>12$ years ( $p=0.002$ compared to $<4$ years). The most common sites of metastases were the liver and lungs. Overall 2-year and 5-year survival rates were $61 \%$ (95\% Cl 45-77) and 46\% (95\% Cl 30-62), respectively. Metastasis at the time of diagnosis was independently associated with poor prognosis (risk ratio $13.7 \% ; 95 \% \mathrm{Cl} 3.9-87.7$ ). Weiss criteria (29\%) and modified Weiss criteria (33\%) were less accurate in younger patients $(<12$ years), compared to the Wieneke index (100\%). Conclusion: The presence of metastases was an independent prognostic factor. The Wieneke index was the most accurate in predicting clinical outcomes in younger children.

(c) 2018 S. Karger AG, Basel

This study was presented as an oral presentation at the 2017 annual meeting of the Endocrine Society (April 2017, Orlando, FL, USA) and received an Endocrine Society Outstanding Abstract Award.
Aida Lteif, MD, or Nidhi Gupta, MD

Division of Pediatric Endocrinology and Metabolism, Mayo Clinic College of Medicine 200 First Street SW

Rochester, MN 55905 (USA)

E-Mail Lteif.Aida@ mayo.edu or gupta.nidhi@ mayo.edu 


\section{Introduction}

Adrenocortical carcinoma (ACC) is a rare but aggressive childhood cancer with a reported incidence of $0.2-$ 0.3 new cases per 1 million children per year [1-4]. There is remarkable geographical variation with the incidence in Southern Brazil being 12-18 times higher than in the United States, likely due to the high prevalence of a founder TP53 mutation in Brazil $[2,5]$. ACC commonly presents with virilization and Cushing syndrome and rarely with feminization and hyperaldosteronism [1, 6-8]. ACC can also be nonfunctional and diagnosed incidentally during the evaluation of abdominal pain, fatigue or other nonspecific symptoms [9]. The majority of ACC are sporadic, but some are associated with a genetic defect. Individuals with the Li-Fraumeni syndrome [10], Beckwith-Wiedemann syndrome [11], multiple endocrine neoplasia type 1 [12], and familial adenomatous polyposis [13] have an increased risk of ACC.

Surgery is the mainstay of treatment. Even after complete resection, a high risk of recurrence of ACC remains. Age $<4$ years, tumor size $<10 \mathrm{~cm}$ [14], virilization alone [15], tumor volume $<200 \mathrm{~cm}^{3}[16,17]$, tumor weight and stage [18], metastatic disease [14], and quality of surgery $[14,19]$ have been suggested as important prognostic markers. Despite multimodality approaches including mitotane [an adrenolytic drug: (o,p'-DDD: 1,1-dichloro-2-o-chlorophenyl)-2-(p-chlorophenyl) ethane], chemotherapy with cisplatin, etoposide and doxorubicin (CED), and radiotherapy, prognosis of pediatric ACC remains poor with an estimated 5-year survival rate ranging from 30 to $90 \%[2,4,15,18,20]$.

There is considerable overlap in clinical, radiological and histological features of ACC and adrenocortical adenoma, which makes decision-making challenging. Due to the rarity and heterogeneity of pediatric ACC, limited evidence exists on a definite histopathological criterion to differentiate ACC from adrenocortical adenomas. The Weiss score is widely used to assess ACC in adults [21]. The modified Weiss score $[9,22]$ and the Wieneke index [18] have been proposed for assessing ACC in pediatrics.

We reviewed the clinicopathological features of 41 pediatric patients with ACC that have been evaluated at the Mayo Clinic over the last 67 years (1950-2017). We also evaluated the validity of the Weiss score, modified Weiss score, and the Wieneke index, all of which have so far been validated in limited pediatric studies $[1,16$, 23].

Pediatric Adrenocortical Carcinoma

\section{Materials and Methods}

\section{Mayo Clinic Adrenal Disorders Database}

The Mayo Clinic Adrenal Disorders Database is a retrospective registry of patients $(n=3,348)$ of any age with adrenal disorders, evaluated at the Mayo Clinic since January 1, 2000. Data on patients from 1950 to 1999 were obtained through the Division of Biomedical Statistics and Informatics at the Mayo Clinic.

\section{Eligibility and Exclusion Criteria}

We searched for patients with clinically and/or pathologically confirmed (based on the Weiss score) diagnosis of ACC (International Classification of Diseases Code ICD-9-CM 194.0 [before September 30, 2015] and ICD-10-CM C74.00, C74.01, C74.02 [after October 1, 2015]) with age at onset of symptoms $\leq 21$ years. Patients evaluated at the Mayo Clinic from January 1, 1950 to October 31, 2017 were included. Patients with adrenocortical adenoma, neuroblastoma, pheochromocytoma, and other tumors of the adrenal medulla were excluded.

\section{Search Methods}

Electronic medical records were available for patients evaluated from 1997 to 2017. Paper medical records were obtained for patients evaluated from 1950 to 1996. Demographics, clinical features, family history, laboratory analysis, radiological findings, surgical data, pathology reports, treatment description, and longterm outcomes were extracted for each patient. Available archived pathology slides $(n=25)$ were reviewed by an expert pathologist (M.R.) and the Weiss score, modified Weiss score, and Wieneke index were determined (see online suppl. Table 1; see www.karger.com/doi/10.1159/000488855 for all online suppl. material) $[9,18,21]$. The pathologist was blinded to patient outcome information. Complete follow-up data were available for 32 patients. Vital statistics of 28 patients were obtained from electronic/paper medical records, of 2 patients from the National Death Index [24], and of 2 patients from direct patient contact. Of the 9 patients who were lost to follow-up, 3 patients were from outside the United States. This study was conducted in accordance with the guidelines of the Code of Federal Regulations (CFR), Title 45, Part 46 and the Institutional Review Board at the Mayo Clinic, Rochester, MN, USA. The requirement to obtain informed consent and assent was waived in accordance with 45 CFR 46.116.

\section{Tumor Staging and Outcome Definitions}

Disease staging was defined according to the European Network for the Study of Adrenal Tumors (ENSAT) classification, i.e., stages I and II were defined as localized tumors $\leq 5$ or $>5 \mathrm{~cm}$, respectively (stage $\mathrm{I}, \mathrm{T}_{1} \mathrm{~N}_{0} \mathrm{M}_{0}$; stage II, $\mathrm{T}_{2} \mathrm{~N}_{0} \mathrm{M}_{0}$ ); stage III was defined as tumors that infiltrated surrounding tissue or displayed positive regional lymph nodes or tumor thrombus in the vena cava /renal vein $\left(\mathrm{T}_{1-2} \mathrm{~N}_{1} \mathrm{M}_{0}\right.$ or $\left.\mathrm{T}_{3-4} \mathrm{~N}_{0-1} \mathrm{M}_{0}\right)$; stage IV consisted of tumors with distant metastases $\left(\mathrm{T}_{1-4} \mathrm{~N}_{0-1} \mathrm{M}_{1}\right)$ (see online suppl. Table 2) $[3,25]$.

Three outcomes of interest were: alive with no evidence of disease, alive with evidence of disease, and dead of disease. The primary endpoints of this study were overall 2-year survival and overall 5-year survival. Time to event was defined as the interval between date of onset of symptoms and date of death resulting from any cause or date of last follow-up.

Horm Res Paediatr 2018;90:8-18 
Table 1. Clinical features at presentation of 41 pediatric patients with adrenocortical carcinoma

\begin{tabular}{|c|c|c|c|c|}
\hline Clinical feature & $\begin{array}{l}\text { Age }<4 \text { years } \\
(n=10)\end{array}$ & $\begin{array}{l}\text { Age } \geq 4 \text { to } \leq 12 \text { years } \\
(n=4)\end{array}$ & $\begin{array}{l}\text { Age }>12 \text { years } \\
(n=27)\end{array}$ & $\begin{array}{l}\text { All patients } \\
(n=41)\end{array}$ \\
\hline \multicolumn{5}{|c|}{ Age at onset of symptoms, years } \\
\hline Median & 0.5 & 7.9 & 16.5 & 15.7 \\
\hline Range & $0.2-2.2$ & $6.5-10.0$ & $12.5-21.0$ & $0.2-21.0$ \\
\hline \multicolumn{5}{|l|}{ Sex, $n$} \\
\hline Female & 7 & 3 & 22 & 32 \\
\hline Male & 3 & 1 & 5 & 9 \\
\hline Female:male ratio & 2.3:1 & $3: 1$ & $4.4: 1$ & $3.6: 1$ \\
\hline \multicolumn{5}{|l|}{ Type of presentation, $n$} \\
\hline Virilization only & 3 & 2 & 2 & 7 \\
\hline Feminization only ${ }^{\mathrm{a}}$ & 0 & 0 & 0 & 0 \\
\hline Cushing syndrome only & 1 & 0 & 1 & 2 \\
\hline Hypertension only & 1 & 0 & 2 & 3 \\
\hline Mixed tumor ${ }^{\mathrm{b}}$ & 4 & 1 & 17 & 22 \\
\hline Nonfunctional tumor & 1 & 1 & 4 & 6 \\
\hline Unknown ${ }^{c}$ & 0 & 0 & 1 & 1 \\
\hline \multicolumn{5}{|l|}{ Duration of symptoms, months } \\
\hline Median & 3.3 & 5.4 & 2.4 & 3.0 \\
\hline Range & $1.2-12$ & $1.2-14.4$ & $1.2-14.4$ & $1.2-14.4$ \\
\hline
\end{tabular}

a Indicated by the presence of gynecomastia in males and premature thelarche in females. ${ }^{\mathrm{b}}$ Indicated by clinical and/or laboratory evidence of abnormal production of more than one hormone, including aldosterone or estrogen. ${ }^{c}$ The patient was diagnosed at another institution and the initial medical records could not be accessed.

\section{Statistical Analysis}

Descriptive analyses were used to present clinical and macroscopic features. Two-year survival and 5-year survival rates were estimated using the Kaplan-Meier method. Heterogeneity in survival among strata of selected variables was assessed using the logrank test. A multivariate Cox proportional hazards model was used to identify factors associated with the risk of mortality. Multivariate hazard ratios, with 95\% CI, were computed considering factors that turned out to be statistically significant at univariate analysis, applying a forward stepwise regression method. Age, disease stage, and metastatic disease were the variables utilized in multivariate regression analysis because complete data on 41 patients were available for these three variables only. Sensitivity, specificity, and accuracy of the Weiss score, modified Weiss score, and Wieneke index were estimated. Clinically benign versus malignant outcomes were compared with pathologically benign versus malignant outcomes. Statistical analysis was performed using JMP Pro version 10.0.0.

\section{Results}

\section{Clinical Features}

Forty-one patients met the prespecified inclusion criteria (Table 1). Median age of all patients at onset of symptoms was 15.7 years (range, $0.2-21$ years). High female preponderance was noted in all age categories with an overall female:male ratio of 3.6:1. Mixed symptomatology representing more than one hormonal abnormality was the most common presentation $(54 \%, n=22)$ followed by virilization alone $(17 \%, n=7)$. Evidence of isolated feminization in males or premature thelarche in females was not noted, except in 1 male patient who presented at 18 years of age with gynecomastia and hypertension. Isolated hyperaldosteronism was reported in 2 patients with onset of symptoms at 16.5 and 19.8 years, respectively. Precocious pubarche was noted in 8 patients, of which 4 were less than 1 year of age, 3 were 1.5-2.2 years and 1 was 7 years old.

Median duration of symptoms before diagnosis of ACC was made was 3.0 months (range, 1.2-14.4 months) ( $p=0.609$ between the three age groups). None of the 41 patients had a known family history of ACC. One patient tested positive for Beckwith Wiedemann syndrome and 1 tested negative for any associated genetic syndromes (Fig. 1).

\section{Macroscopic Features}

Sixty-six percent of the patients $(n=27$ of 41$)$ underwent total adrenalectomy (Table 2). ACC was described
10

Horm Res Paediatr 2018;90:8-18 DOI: $10.1159 / 000488855$
Gupta/Rivera/Novotny/Rodriguez/ Bancos/Lteif 
Fig. 1. Photograph of our patient. A 3-yearold girl with adrenocortical carcinoma. She presented at 1.8 years of age with pubic hair, body odor, exponential weight gain, and stunting of growth velocity. a At 2 years of age prior to right adrenalectomy. b Patient 1 year later with no recurrence. c, d Surgical specimen of resected and encapsulated adrenocortical carcinoma. The tumor measured $6.2 \times 5.8 \times 4.1 \mathrm{~cm}$ and weighed $93 \mathrm{~g}$.
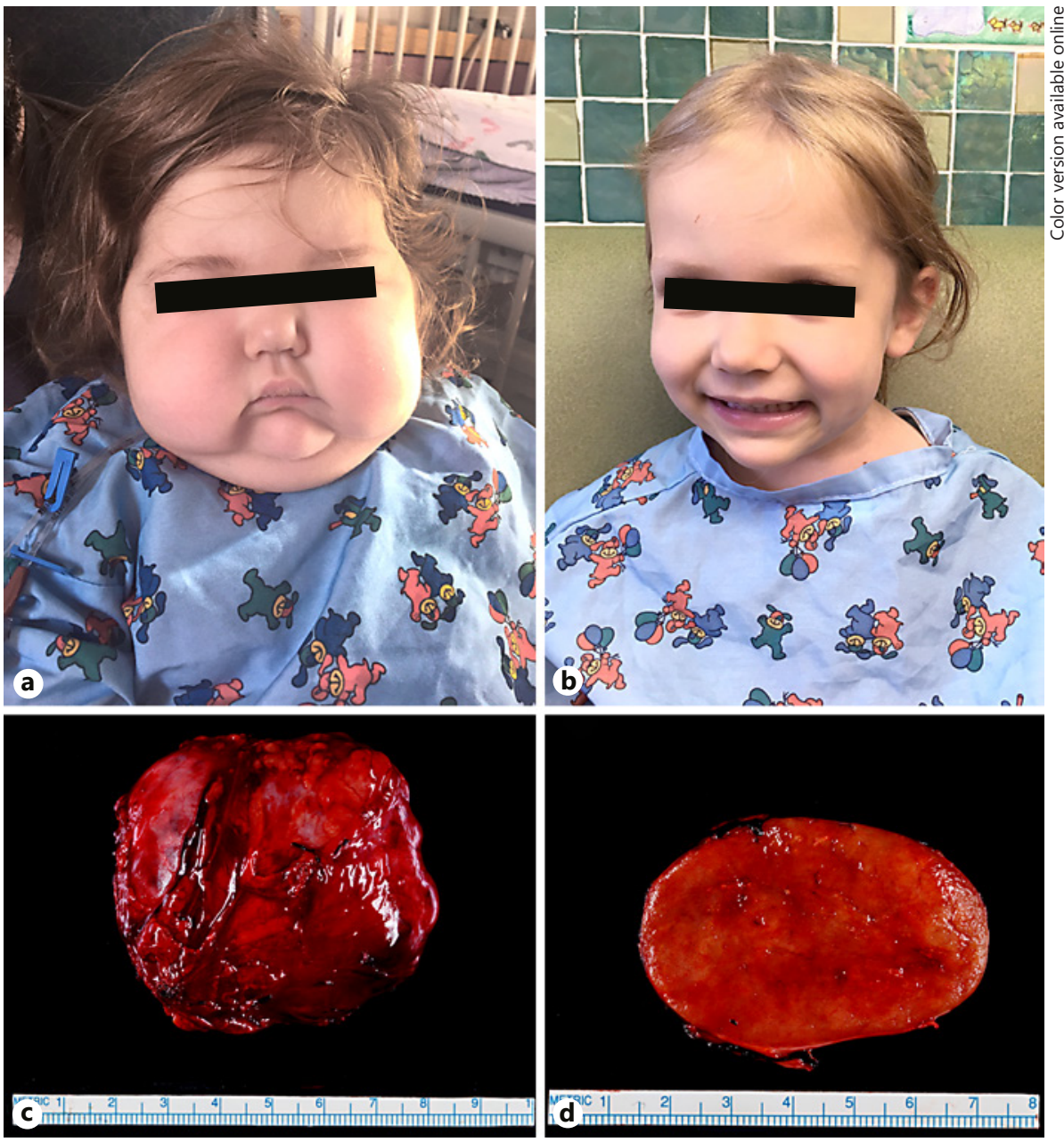

as inoperable in 4 patients, all of whom were $>12$ years old. Patients aged $<4$ years had a smaller median tumor diameter and lower median tumor weight as compared to those aged $\geq 12$ years (tumor diameter: 6.4 vs. $10.8 \mathrm{~cm}$; tumor weight: 80 vs. $435 \mathrm{~g}, p<0.005$ for both). The tumor was localized to the adrenal gland in 15 out of the 36 patients $(42 \%)$ for whom these data were available.

Metastatic disease was less frequent in patients aged $<4$ years ( 2 out of $10 ; 20 \%$ ), compared to those aged $>12$ years (22 out of $27 ; 81 \%)(p=0.002)$. Overall, the most common sites of metastases were the liver (73\%), lungs (69\%), and retroperitoneal lymph nodes (27\%). A majority of patients $(n=26,63 \%)$ were classified by the ENSAT system as stage IV $\left(\mathrm{T}_{1-4} \mathrm{~N}_{0-1} \mathrm{M}_{1}\right)$.

\section{Treatment Outcomes}

Stage I $(n=2)$

After resection of the primary spinal adrenocortical tumor at 5 months and recurrent spinal lesion at 11 months, 1 patient was treated with mitotane and 8 cycles of CED. She was in complete remission at 6.3 years. The second patient underwent surgery at 1.8 years, manifested high-grade chondroblastic osteosarcoma of the right sacroiliac area at 16 years, and was treated with hemipelvectomy, cisplatin, doxorubicin, and methotrexate.

\section{Stage II $(n=11)$}

All patients were treated with surgery only. Six patients are alive with no evidence of disease (outcome unknown for 4 patients). One patient developed local recurrence and died a year after resection of recurrent lesion. One patient was diagnosed with familial adenomatous 
Table 2. Macroscopic features of 41 pediatric patients with adrenocortical carcinoma

\begin{tabular}{|c|c|c|c|c|}
\hline Macroscopic feature & $\begin{array}{l}\text { Age }<4 \text { years } \\
(n=10)\end{array}$ & $\begin{array}{l}\text { Age } \geq 4 \text { to } \leq 12 \text { years } \\
(n=4)\end{array}$ & $\begin{array}{l}\text { Age }>12 \text { years } \\
(n=27)\end{array}$ & $\begin{array}{l}\text { All patients } \\
(n=41)\end{array}$ \\
\hline \multicolumn{5}{|l|}{ Surgery, $n$} \\
\hline Partial adrenalectomy & 1 & 0 & 2 & 3 \\
\hline Total adrenalectomy & 7 & 3 & 17 & 27 \\
\hline Radical resection & 1 & 1 & 4 & 6 \\
\hline Inoperable & 0 & 0 & 4 & 4 \\
\hline \multicolumn{5}{|l|}{ Primary site, $n$} \\
\hline Right & 5 & 1 & 11 & 17 \\
\hline Left & 4 & 3 & 16 & 23 \\
\hline Other & $1^{\mathrm{a}}$ & 0 & 0 & 1 \\
\hline \multicolumn{5}{|l|}{ Maximum tumor diameter ${ }^{\mathrm{c}}, \mathrm{cm}$} \\
\hline Median & 6.4 & 9.8 & 10.8 & 9.5 \\
\hline \multicolumn{5}{|l|}{ Tumor weight ${ }^{\mathrm{d}}, \mathrm{g}$} \\
\hline \multicolumn{5}{|l|}{ Tumor extension, $n$} \\
\hline Localized to adrenal gland & 5 & 2 & 8 & 15 \\
\hline Extending into adjacent tissue & 3 & 2 & 11 & 16 \\
\hline Extending into adjacent organ & 0 & 0 & 5 & 5 \\
\hline Other & $2^{\mathrm{a}, \mathrm{b}}$ & 0 & $3^{\mathrm{b}}$ & 5 \\
\hline \multicolumn{5}{|l|}{ Vena cava invasion, $n$} \\
\hline Present & 0 & 0 & 5 & 5 \\
\hline Absent & 7 & 3 & 10 & 20 \\
\hline Other & $3^{\mathrm{a}, \mathrm{b}}$ & $1^{\mathrm{b}}$ & $12^{\mathrm{b}}$ & 16 \\
\hline \multicolumn{5}{|l|}{ Metastatic disease, $n$} \\
\hline No metastases & 8 & 2 & 5 & 15 \\
\hline Lung only & 0 & 0 & 3 & 3 \\
\hline Stage I & 2 & 0 & 0 & 2 \\
\hline Stage II & 5 & 2 & 4 & 11 \\
\hline Stage III & 1 & 0 & 1 & 2 \\
\hline Stage IV & 2 & 2 & 22 & 26 \\
\hline \multicolumn{5}{|l|}{ Type of treatment, $n$} \\
\hline Surgery only & 8 & 2 & 10 & 20 \\
\hline Surgery + chemotherapy & 2 & 2 & 13 & 17 \\
\hline Inoperable (chemotherapy + radiotherapy) & 0 & 0 & 4 & 4 \\
\hline
\end{tabular}

${ }^{a}$ Resection of primary spinal adrenocortical carcinoma in 1 patient. ${ }^{b}$ Data not available. ${ }^{c}$ Based on operative or pathology report; estimated from imaging if tumor was inoperable. ${ }^{\mathrm{d}}$ Data was available for: age group $<4$ years, $n=9$; for age group $\geq 4$ to $\leq 12$ years, $n=3$, for age group $>12$ years, $n=14$, for all patients, $n=26$. ${ }^{\mathrm{e}}$ Brain; cervical and thoracic spinal cord. ${ }^{\mathrm{f}}$ Liver, lumbar spine and parietal bone. ${ }^{\mathrm{g}}$ Included combinations of $\geq 2$ of these sites: lung $(n=11)$, liver $(n=10)$, thoracic vertebrae $(n=2)$, bones $(n=2)$, kidney $(n=2)$, spleen $(n=2)$, brain $(n=1)$, ovary $(n=1)$, retroperitoneum $(n=4)$, retroperitoneal lymph nodes $(n=7)$, mediastinal lymph nodes $(n=3)$, supraclavicular lymph nodes $(n=1)$, left pulmonary artery $(n=1) .{ }^{\mathrm{h}}$ At the site of the primary tumor. ${ }^{\mathrm{i}} \mathrm{ENSAT}$, European Network for the Study of Adrenal Tumors. Stage I, $\mathrm{T}_{1} \mathrm{~N}_{0} \mathrm{M}_{0}$; stage II, $\mathrm{T}_{2} \mathrm{~N}_{0} \mathrm{M}_{0}$; stage III, $\mathrm{T}_{1-2} \mathrm{~N}_{1} \mathrm{M}_{0}$ or $\mathrm{T}_{3-4} \mathrm{~N}_{0-1} \mathrm{M}_{0}$; stage IV, $\mathrm{T}_{1-4} \mathrm{~N}_{0-1} \mathrm{M}_{1}$. 
Table 3. Kaplan-Meier analysis for 2-year survival and 5-year survival (univariate analysis)

\begin{tabular}{|c|c|c|c|c|}
\hline Feature & Number $^{a}$ & $\begin{array}{l}\text { 2-year survival, } \\
\%(95 \% \mathrm{CI})\end{array}$ & $\begin{array}{l}\text { 5-year survival, } \\
\%(95 \% \mathrm{CI})\end{array}$ & $\begin{array}{l}\text { log-rank } \\
p \text { value }\end{array}$ \\
\hline All patients & 41 & $61(45-77)$ & $46(30-62)$ & \\
\hline \multicolumn{5}{|l|}{ Age } \\
\hline$<4$ years & 10 & $100(-)$ & $100(-)$ & \multirow[t]{3}{*}{$0.002^{*}$} \\
\hline$\geq 4$ to $\leq 12$ years & 4 & $75(32-100)$ & $75(32-100)$ & \\
\hline$>12$ years & 27 & $43(23-63)$ & $21(5-37)$ & \\
\hline \multicolumn{5}{|l|}{ Sex } \\
\hline Female & 32 & $63(45-81)$ & $48(30-66)$ & \multirow[t]{2}{*}{0.654} \\
\hline Male & 9 & $56(23-89)$ & $42(9-75)$ & \\
\hline \multicolumn{5}{|l|}{ Type of presentation } \\
\hline Virilization only & 7 & $86(61-100)$ & $86(61-100)$ & \multirow[t]{3}{*}{0.352} \\
\hline Mixed tumor & 22 & $56(34-78)$ & $28(8-48)$ & \\
\hline Nonfunctional & 6 & $50(11-89)$ & $50(11-89)$ & \\
\hline \multicolumn{5}{|l|}{ Maximum tumor diameter } \\
\hline$<10 \mathrm{~cm}$ & 18 & $87(69-100)$ & $80(60-100)$ & \multirow[t]{2}{*}{$0.001^{*}$} \\
\hline$\geq 10 \mathrm{~cm}$ & 21 & $46(24-68)$ & $26(6-46)$ & \\
\hline \multicolumn{5}{|l|}{ Tumor weight } \\
\hline$<400 \mathrm{~g}$ & 16 & $93(81-100)$ & $85(67-100)$ & \multirow[t]{2}{*}{$0.002 *$} \\
\hline$\geq 400 \mathrm{~g}$ & 10 & $50(19-81)$ & $20(0-45)$ & \\
\hline \multicolumn{5}{|l|}{ Tumor extension } \\
\hline Localized to adrenal gland & 15 & $86(68-100)$ & $78(56-100)$ & \multirow[t]{3}{*}{$0.001^{*}$} \\
\hline Extending into adjacent tissue & 16 & $48(23-73)$ & $27(5-49)$ & \\
\hline Extending into adjacent organ & 5 & $40(0-83)$ & $0(-)$ & \\
\hline \multicolumn{5}{|l|}{ Metastatic disease } \\
\hline Yes & 26 & $39(19-59)$ & $18(0.4-36)$ & \multirow[t]{2}{*}{$<0.0001^{*}$} \\
\hline No & 15 & $93(81-100)$ & $86(68-100)$ & \\
\hline \multicolumn{5}{|l|}{ Tumor stage } \\
\hline I-II & 13 & $100(-)$ & $92(76-100)$ & \multirow[t]{2}{*}{$<0.001^{*}$} \\
\hline III-IV & 28 & $40(20-60)$ & $21(3-39)$ & \\
\hline
\end{tabular}

${ }^{\text {a }}$ Missing values were excluded. ${ }^{*} p<0.05$.

polyposis, which was treated with subtotal colectomy and chemotherapy.

Stage III $(n=2)$

One patient with the Beckwith-Wiedemann syndrome was treated with surgery at 6 months and is alive with no evidence of disease. The second patient received surgery and mitotane and died 5 months after diagnosis, at 21 years.

\section{Stage IV $(n=26)$}

Four patients had inoperable, metastatic ACC and died of disease 1-8 months after diagnosis (adjuvant therapy: radiotherapy in 2 , mitotane in 1 , mitotane, cisplatin and etoposide in 1). Three patients were treated with surgery and died at $10-17$ years (0.6-9.4 years after diagnosis). After resection of the primary tumor, the remaining
19 patients received chemotherapy (mitotane in 6; varying combinations of CED, mitotane, paclitaxel, mitoxantrone, 5-fluorouracil, gemcitabine, bleomycin, docetaxel, cyclophosphamide, carboplatin, and ifosfamide in 13). Of these 19 patients, 14 died at a median age of 1.35 years from diagnosis (range, $0.2-7.8$ years), 1 is alive without evidence of disease, and outcome is unknown for 4 .

\section{Survival Analysis}

Overall 2-year survival rate was 61\% (95\% CI 45-77). Overall 5-year survival rate was 46\% (95\% CI 30-62) (Table 3). In univariate analysis, age $<4$ years, maximum tumor diameter $<10 \mathrm{~cm}$, tumor weight $<400 \mathrm{~g}$, tumor localization to adrenal gland, absence of metastatic disease at the time of diagnosis, and low stage (I/II) were associated with better 2-year survival and 5-year survival. KaplanMeier survival curves are shown in Figure 2. Applying a 
Table 4. Clinical outcomes in patients considered to have malignant versus benign pathology based on three histopathological criteria ${ }^{\text {a-c }}$

\begin{tabular}{|c|c|c|c|c|c|c|c|c|c|c|c|c|}
\hline \multirow[t]{2}{*}{ Criteria } & \multicolumn{4}{|c|}{ Age $\leq 12$ years } & \multicolumn{4}{|c|}{ Age $>12$ years } & \multicolumn{4}{|c|}{ All patients } \\
\hline & $n$ & AND & AWD & DOD & $n$ & AND & AWD & DOD & $n$ & AND & AWD & DOD \\
\hline Weiss & 6 & 5 & - & 1 & 14 & 1 & 1 & 12 & 20 & 6 & 1 & 13 \\
\hline Modified Weiss & 5 & 4 & - & 1 & 11 & 1 & 2 & 8 & 16 & 5 & 2 & 9 \\
\hline Wieneke index & 1 & - & - & 1 & 10 & - & 1 & 9 & 11 & - & 1 & 10 \\
\hline Weiss & 1 & 1 & - & - & 0 & - & - & - & 1 & 1 & - & - \\
\hline Modified Weiss & 1 & 1 & - & - & 0 & - & - & - & 1 & 1 & - & - \\
\hline Wieneke index & 5 & 5 & - & - & 2 & 2 & - & - & 7 & 7 & - & - \\
\hline
\end{tabular}

AND, alive with no evidence of disease; AWD, alive with evidence of disease; DOD, dead of disease. ${ }^{\text {a }}$ Malignant pathology was defined by Weiss score $\geq 3$, modified Weiss score $\geq 3$, Wieneke index score $\geq 4$. ${ }^{b}$ Data are presented only for patients on whom complete histological and clinical outcomes were known. "Age groups " $<4$ years" and " $\geq 4$ to $\leq 12$ years" were combined due to limited sample size in the latter age group.

Fig. 2. Probability of 2-year survival and 5 -year survival of 41 pediatric patients with adrenocortical carcinoma. a All patients; 2-year survival 61\% (95\% CI 45-77); 5-year survival 46\% (95\% CI 30-62). b Survival according to age at the time of onset of symptoms. c Survival according to presence of metastases at the time of diagnosis. d Survival according to disease stage at the time of diagnosis.

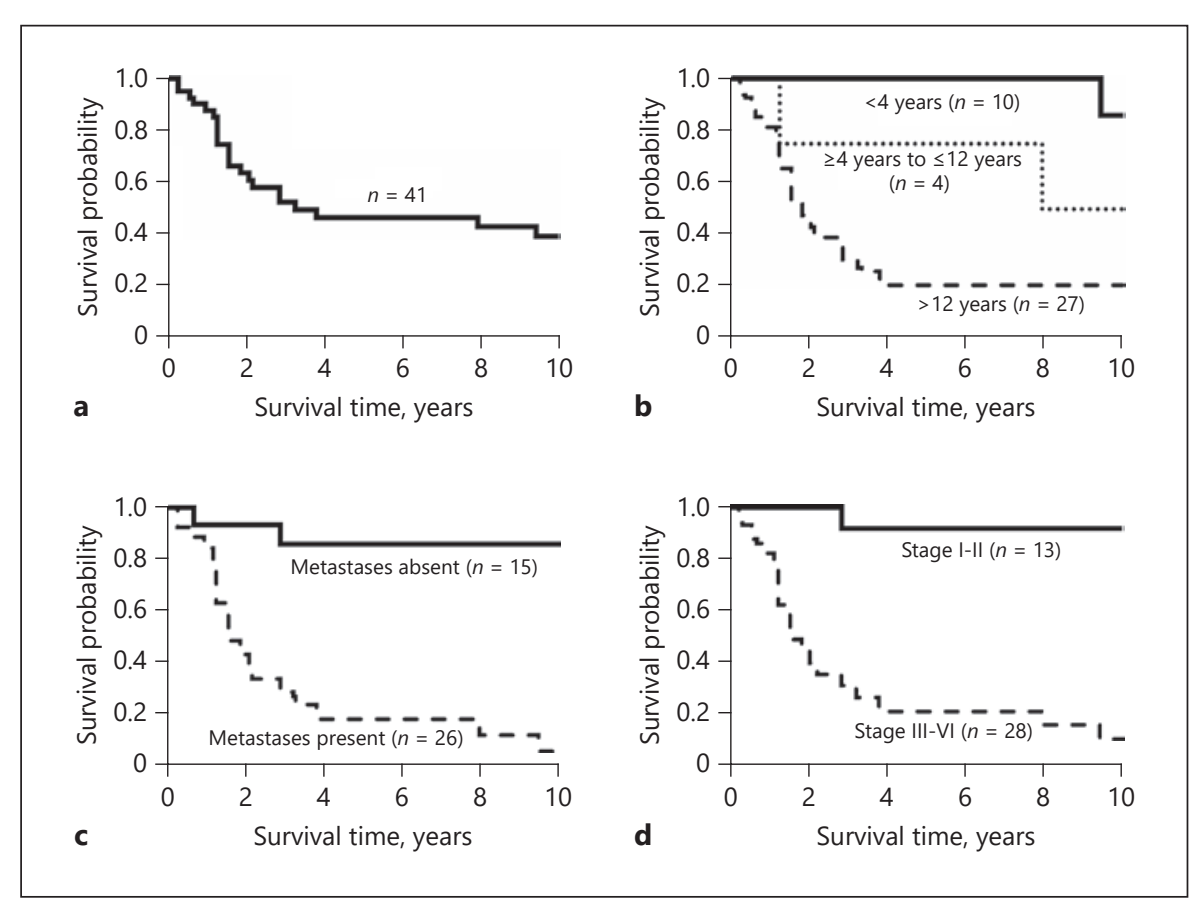

forward stepwise regression method using age, disease stage, and metastatic disease, presence of metastases at the time of diagnosis of ACC was the only independent factor associated with poor prognosis (risk ratio 13.7\%; 95\% CI 3.9-87.7).

\section{Accuracy of Histopathological Criteria}

Outcomes that were clinically benign versus malignant were analyzed based on the pathological features of the tumor (Table 4). A malignant pathology was defined by a Weiss score $\geq 3$, modified Weiss score $\geq 3$, and Wieneke index score $\geq 4$. Data on clinical outcomes as well as pathology were available for a smaller number of patients ( $n=21$ for Weiss criteria, $n=17$ for modified Weiss criteria, $n=18$ for Wieneke index). Therefore, a clear assessment of performance of each criterion could not be made. However, certain trends were noted (Table $5)$. Weiss criteria were less accurate in the younger pa- 
Table 5. Accuracy of the three histopathological criteria

\begin{tabular}{|c|c|c|c|c|c|c|c|c|c|c|}
\hline \multirow[t]{2}{*}{ Criteria } & \multicolumn{5}{|c|}{ Age $\leq 12$ years } & \multicolumn{5}{|c|}{ Age $>12$ years } \\
\hline & $\begin{array}{l}\text { sensitivity, } \\
\%\end{array}$ & $\begin{array}{l}\text { specificity, } \\
\%(95 \% \mathrm{CI})\end{array}$ & $\begin{array}{l}\text { PPV, } \\
\%\end{array}$ & $\begin{array}{l}\text { NPV, } \\
\%\end{array}$ & $\begin{array}{l}\text { accuracy, } \\
\%\end{array}$ & $\begin{array}{l}\text { sensitivity, } \\
\%\end{array}$ & $\begin{array}{l}\text { specificity, } \\
\%(95 \% \text { CI) }\end{array}$ & $\begin{array}{l}\mathrm{PPV}, \\
\%\end{array}$ & $\begin{array}{l}\text { NPV, } \\
\%\end{array}$ & $\begin{array}{l}\text { accuracy, } \\
\%\end{array}$ \\
\hline Weiss & 100 & $17(1-64)$ & 17 & 100 & 29 & 100 & $0(0-97)$ & 93 & - & 93 \\
\hline Modified Weiss & 100 & $20(1-72)$ & 20 & 100 & 33 & 100 & $0(0-98)$ & 91 & - & 91 \\
\hline Wieneke index & 100 & $100(48-100)$ & 100 & 100 & 100 & 100 & $100(16-100)$ & 100 & 100 & 100 \\
\hline
\end{tabular}

PPV, positive predictive value; NPV, negative predictive value; -, insufficient $n$.

tients ( $29 \%$ in $\leq 12$ years vs. $93 \%$ in $>12$ years). Modified Weiss criteria were also less accurate in the younger patients $(33 \%$ in $\leq 12$ years vs. $91 \%$ in $>12$ years). The Wieneke index was more accurate than Weiss and modified Weiss criteria in both age groups. A significant overlap in $95 \%$ CI for specificity was noted for all three criteria, thereby limiting the interpretation of these results.

\section{Discussion}

The findings from this study provide strong evidence that the natural course of ACC is significantly different and favorable in children younger than 4 years of age compared to those older than 12 years of age. Presence of metastases at the time of diagnosis of ACC is an independent prognostic factor for survival. Histopathological classification of ACC in pediatrics remains controversial. The Wieneke index was the most accurate in predicting clinical outcomes in younger children in our study.

\section{Biphasic Age Distribution}

Adrenocortical tumors (ACT) have been reported to have either early age of onset ( $<4$ years) $[3,9,14-16]$ or biphasic age distribution ( $<5$ years and $>10$ years) $[18$, $26]$. These studies included patients from Brazil $[9,15]$, the USA [14, 18], the Netherlands [3], Turkey [26], and other countries [27], thereby disputing any geographical pattern. A majority of our patients, which was primarily an American cohort, had onset of symptoms after 12 years of age.

Limited data are available on the onset and course of ACT during early infancy [28-33]. In the International Pediatric Adrenocortical Tumor Registry (IPACTR), $12 \%$ of cases (adenomas and carcinomas combined) were diagnosed during the first year of life [15]. Seven of our patients (17\%) had onset of symptoms within the first year of life. Three of these patients are alive with no evidence of disease (at 3 years, 18 years and 38 years of age), 1 died at 10 years, and outcome was not known on the remaining 3 patients. Previous reports have suggested favorable outcomes after treatment in infantile ACC [30, 31,33 . A newborn girl had spontaneous regression of skin metastases and cerebral lesion by 4 months of age following surgical resection of right adrenal primary tumor [29]. On the other hand, poor clinical outcomes were described by Satge et al. [28] in 14 children with congenital ACT.

\section{Variability in Clinical Presentation}

Consistent with previous studies [3, 9, 15, 16, 26, 34], mixed symptomatology (virilization, Cushing syndrome, and hyperaldosteronism) was the most common presentation of ACC across all age groups in our cohort. One patient presented at 5 months of age with lower extremity weakness and was diagnosed with ectopic extramedullary intradural ACC with 2 intact adrenal glands. Ectopic $\mathrm{ACT}$ are rare and have been described previously in the spinal canal [35] and intrathoracic cavity [36].

Nonfunctional tumors comprised $12 \%$ of our patients. Fifteen percent of patients older than 12 years had nonfunctional presentation, compared to only $0.1 \%$ nonfunctional tumors in less than 4-year-olds. About $20-30 \%$ of adult ACC present as nonfunctional tumors [37], suggesting likely resemblance of the natural course of ACC in adults with that in older children, compared to younger children. This further supports the hypothesis proposed by Michalkiewicz et al. [15] that "ACTs comprise at least two distinct subtypes based on age at onset." In IPACTR, nonfunctional tumors were observed in $10.2 \%$ of patients (median age 3.2 years; range, 0-19 years); however, data included adrenal adenomas and carcinomas [15]. 


\section{Treatment Strategies and Outcomes}

Our patients were treated with adjuvant therapy in settings of metastatic, recurrent, inoperable or stage IV disease. In IPACTR [15], for localized disease, surgery alone was recommended. However, $12 \%$ of patients with stage I or II received adjuvant chemotherapy including CED and mitotane. Stage III or IV tumors were treated with intensive chemotherapy. Recurrent disease was treated with surgical resection, if feasible, always followed by chemotherapy. A similar treatment approach was employed by Dall'Igna et al. [16] in 58 Italian children enrolled in a prospective national study (TREP; Rare Tumors in Pediatric Age). In a cohort of 111 children with ACC from the National Cancer Database (NCDB), adjuvant systemic therapy was utilized in $30 \%$ of children who underwent surgical resection [14].

Redlich et al. [38] described treatment outcomes of 60 German patients (age $0.24-17.8$ years) treated according to the nonrandomized, single-arm study GPOH-MET-97. Chemotherapy with vincristine, ifosfamide, carboplatin, etoposide, and doxorubicin was provided to 34 patients (56.6\%) and mitotane therapy to 32 patients (53.3\%). Mitotane treatment longer than 6 months and mitotane levels greater than $14 \mathrm{mg} / \mathrm{L}$ were found to be associated with significantly better survival. Radiation therapy alone or in combination with chemotherapy has rarely been used in previous studies $[3,15,18]$.

Mitotane has been associated with significant gastrointestinal, neuropsychiatric and hepatic toxicity $[38,39]$. Twenty patients in our study were treated with mitotane in different settings (neoadjuvant, adjuvant, and salvage), with doses ranging from 0.5 to $10 \mathrm{~g}$ per day. Of these 20 patients, 15 died of disease, 1 is alive with no evidence of disease and outcome is unknown for 4 patients. Adverse effects noted in our patients included sedation, depression, blurred vision, gastrointestinal symptoms, extremity weakness, ototoxicity, mild renal insufficiency, bone marrow suppression, and drug reaction. Mitotane had to be discontinued within 6 weeks to 6 months in 7 patients due to intolerable side effects. Godil et al. [33] reported multiple additional complications including seizures, gynecomastia, and abnormal thyroid function tests in a neonate with metastasizing congenital ACC. These issues resolved after discontinuation of mitotane.

\section{Survival and Prognosis}

Overall 2-year and 5-year survival rates (61 and 46\%, respectively) of our patients were comparable to those reported previously $[4,14,15,17]$. In IPACTR [15], at a median follow-up of 2 years and 5 months, $61.8 \%$ patients remained alive. The 5-year overall survival estimate was 54.7\% (95\% CI 48.7-60.7). The age at which survival declines remains unclear. Results from the Surveillance, Epidemiology, and End Results (SEER) database indicated that overall 5-year survival for patients younger than 4 years was $91.1 \%$ (95\% CI 74.8-97.1) and that it reduced significantly for patients aged 5-19 years to $29.8 \%$ (95\% CI 16.8-44.1) [4]. Age less than 4 years was an important predictor of survival in our patients as well as in several other cohorts $[3,14-16]$. This was likely related to a smaller tumor size $(<10 \mathrm{~cm})$ [18], lower tumor weight $(<400 \mathrm{~g})$, lower tumor volume $\left(<200 \mathrm{~cm}^{3}\right)$ [16], disease localized to adrenal gland $[14,18]$, less advanced disease (stage I/II) [15], and lower incidence of metastatic disease in younger children compared to older ones [14].

\section{Histopathological Classification}

Rarity of ACC and lack of data on association between histopathological features and clinical outcomes contribute to this puzzle. We found that the majority of our patients younger than 12 years of age had a clinically benign outcome despite malignant histological features based on Weiss criteria [21] and modified Weiss criteria [8, 22]. Investigators have reported similar discrepancy between correlation of histological classification of ACC based on adult criteria (specifically Weiss criteria) and patient outcomes $[16,18,40]$. Correlation between high Weiss score and worse clinical outcomes was not observed in 12 Dutch children (median age 4.1 years); however, stronger correlation was noted with application of the Wieneke index instead, though their sample size was small $[3,18]$.

Validity of the Wieneke index was further demonstrated by Chatterjee et al. [1, 41], in a group of 13 children with ACT (mean age 2.9 years). Applying the Wieneke index, 6 patients were assigned to benign, 1 to the intermediate, and 6 to the malignant pathology group, which was eventually consistent with the clinical behavior of these tumors. However, when Weiss criteria were applied, 3 tumors with benign clinical behavior were assigned to malignant pathology. The Wieneke index was applied in 24 Italian children (median age 5 years) with good significance [16]. Our findings corroborated that the Wieneke index was more accurate in predicting clinical outcomes at least in younger children. However, considering that adrenocortical adenomas were excluded from the study, false-positive cases may have been underestimated.
16

Horm Res Paediatr 2018;90:8-18 DOI: $10.1159 / 000488855$
Gupta/Rivera/Novotny/Rodriguez/ Bancos/Lteif 


\section{Limitations and Strengths}

Our study had certain limitations including the retrospective nature of the data. Genetic testing was not performed on the majority of the patients (except 2), primarily due to lack of availability of genetic testing over the study period. Therefore, no conclusion regarding association of TP53 mutations with ACC could be made. Information on immunohistochemical staining was lacking, though validity of these stains in pediatrics has not been established [18]. As mentioned previously, histopathological and mortality data were available for a limited number of patients, which made definite validation of histopathological criteria challenging. Data on growth abnormalities and endocrine laboratory evaluation were available for a limited number of patients as well.

The Mayo Clinic is a tertiary care referral center. Our cohort included local, regional and international patients over the last 6 decades, some of whom had undergone initial diagnostic evaluation and management elsewhere. These patients might have received treatment that differs from current practice at the Mayo Clinic. In pediatric ACC, various registries have utilized either the IPACTR or ENSAT staging system $[3,15,16]$. We did not use the IPACTR staging system because that requires data on postoperative hormonal levels, tumor margin status, and presence of microscopic residual tumor [2]. These data were not available for a majority of our patients.

The strengths of our study relate to the measures undertaken to reduce the effect of bias in histological interpretation of archived pathological slides. We acknowl- edge that larger studies on pediatric ACT (adenomas plus carcinomas) have been published previously. These studies have reported cohorts of patients from multicenter registries over a period of 10-35 years $[1,3,4,14-17,26$, 42]. Our study is the largest single institution experience with longest duration of data on pediatric ACC, reported so far.

\section{Conclusions}

ACC in younger children has a distinct natural history compared to older children. Though age $<4$ years was an important predictor of survival in our study, metastatic disease at the time of diagnosis of ACC was an independent prognostic factor. Based on our findings, we advocate utilization of the Wieneke index (in conjunction with clinical features) in predicting outcomes at least in younger children, though validation studies with a larger sample size are required. Efficacy of adjuvant systemic therapy remains unclear. We recommend observation after complete surgical resection in patients with localized disease and a low Wieneke index score $(<4)$. Collaborative, international prospective trials with various adjuvant therapy options would be the ideal next step.

\section{Disclosure Statement}

The authors declare that there are no conflict of interests.

\section{References}

1 Chatterjee G, DasGupta S, Mukherjee G, Sengupta M, Roy P, Arun I et al. Usefulness of Wieneke criteria in assessing morphologic characteristics of adrenocortical tumors in children. Pediatr Surg Int. 2015 Jun;31(6): $563-71$.

2 Sandrini R, Ribeiro RC, DeLacerda L. Childhood adrenocortical tumors. J Clin Endocrinol Metab. 1997 Jul;82(7):2027-31.

3 Kerkhofs TM, Ettaieb MH, Verhoeven RH, Kaspers GJ, Tissing WJ, Loeffen J et al. Adrenocortical carcinoma in children: first population-based clinicopathological study with long-term follow-up. Oncol Rep. 2014 Dec; 32(6):2836-44.

4 McAteer JP, Huaco JA, Gow KW. Predictors of survival in pediatric adrenocortical carcinoma: a Surveillance, Epidemiology, and End Results (SEER) program study. J Pediatr Surg. 2013 May;48(5):1025-31.
5 Rodriguez-Galindo C, Figueiredo BC, Zambetti GP, Ribeiro RC. Biology, clinical characteristics, and management of adrenocortical tumors in children. Pediatr Blood Cancer. 2005 Sep;45(3):265-73.

6 Wajchenberg BL, Albergaria Pereira MA, Medonca BB, Latronico AC, Campos Carneiro P, Alves VA et al. Adrenocortical carcinoma: clinical and laboratory observations. Cancer. $2000 \mathrm{Feb} ; 88(4): 711-36$.

7 Frasch W, Gnekow A, Bolkenius M, Wagner T, Dhom G, Dörr HG et al. Adrenal cortex carcinoma. A rare cause of a Conn syndrome in childhood. Monatsschr Kinderheilkd. 1992 Feb;140(2):95-101.

8 Ribeiro RC, Figueiredo B. Childhood adrenocortical tumours. Eur J Cancer. 2004 May; 40(8):1117-26.
9 Ribeiro RC, Michalkiewicz EL, Figueiredo BC, DeLacerda L, Sandrini F, Pianovsky MD et al. Adrenocortical tumors in children. Braz J Med Biol Res. 2000 Oct;33(10):1225-34.

10 Kleihues $P$, Schäuble $B$, zur Hausen $A$, Estève J, Ohgaki $\mathrm{H}$. Tumors associated with p53 germline mutations: a synopsis of 91 families. Am J Pathol. 1997 Jan;150(1):1-13.

11 Lapunzina P. Risk of tumorigenesis in overgrowth syndromes: a comprehensive review. Am J Med Genet C Semin Med Genet. 2005 Aug;137C(1):53-71.

12 Gatta-Cherifi B, Chabre O, Murat A, Niccoli $\mathrm{P}$, Cardot-Bauters C, Rohmer V et al. Adrenal involvement in MEN1. Analysis of 715 cases from the Groupe d'etude des Tumeurs Endocrines database. Eur J Endocrinol. $2012 \mathrm{Feb}$; 166(2):269-79. 
13 Gaujoux S, Pinson S, Gimenez-Roqueplo AP, Amar L, Ragazzon B, Launay P et al. Inactivation of the APC gene is constant in adrenocortical tumors from patients with familial adenomatous polyposis but not frequent in sporadic adrenocortical cancers. Clin Cancer Res. 2010 Nov; 16(21):5133-41.

14 Gulack BC, Rialon KL, Englum BR, Kim J, Talbot LJ, Adibe OO et al. Factors associated with survival in pediatric adrenocortical carcinoma: An analysis of the National Cancer Data Base (NCDB). J Pediatr Surg. 2016 Jan; 51(1):172-7.

15 Michalkiewicz E, Sandrini R, Figueiredo B, Miranda EC, Caran E, Oliveira-Filho AG et al. Clinical and outcome characteristics of children with adrenocortical tumors: a report from the International Pediatric Adrenocortical Tumor Registry. J Clin Oncol. 2004 Mar; 22(5):838-45.

16 Dall'Igna P, Virgone C, De Salvo GL, Bertorelle R, Indolfi P, De Paoli A et al. Adrenocortical tumors in Italian children: analysis of clinical characteristics and P53 status. Data from the national registries. J Pediatr Surg. 2014 Sep;49(9):1367-71.

17 Cecchetto G, Ganarin A, Bien E, Vorwerk P, Bisogno G, Godzinski J et al. Outcome and prognostic factors in high-risk childhood adrenocortical carcinomas: A report from the European Cooperative Study Group on Pediatric Rare Tumors (EXPeRT). Pediatr Blood Cancer. 2017 Jun;64(6):64.

18 Wieneke JA, Thompson LD, Heffess CS. Adrenal cortical neoplasms in the pediatric population: a clinicopathologic and immunophenotypic analysis of 83 patients. Am J Surg Pathol. 2003 Jul;27(7):867-81.

19 Teinturier C, Pauchard MS, Brugières L, Landais $\mathrm{P}$, Chaussain JL, Bougnères PF. Clinical and prognostic aspects of adrenocortical neoplasms in childhood. Med Pediatr Oncol. 1999 Feb;32(2):106-11.

20 Redlich A, Boxberger N, Strugala D, Frühwald MC, Leuschner I, Kropf S et al. Systemic treatment of adrenocortical carcinoma in children: data from the German GPOH-MET 97 trial. Klin Padiatr. 2012 Oct;224(6):36671.

21 Weiss LM. Comparative histologic study of 43 metastasizing and nonmetastasizing adrenocortical tumors. Am J Surg Pathol. 1984 Mar; $8(3): 163-9$
22 Bugg MF, Ribeiro RC, Roberson PK, Lloyd RV, Sandrini R, Silva JB et al; Brazilian Group for Treatment of Childhood Adrenocortical Tumors. Correlation of pathologic features with clinical outcome in pediatric adrenocortical neoplasia. A study of a Brazilian population. Am J Clin Pathol. 1994 May;101(5): 625-9.

23 Magro G, Esposito G, Cecchetto G, Dall'Igna P, Marcato R, Gambini C et al. Pediatric adrenocortical tumors: morphological diagnostic criteria and immunohistochemical expression of matrix metalloproteinase type 2 and human leucocyte-associated antigen (HLA) class II antigens. Results from the Italian Pediatric Rare Tumor (TREP) Study project. Hum Pathol. 2012 Jan;43(1):31-9.

24 National Death Index. National center for health statistics 2015 [cited 2016 June 17]. Available from: http://www.cdc.gov/nchs/ ndi/index.html.

25 Fassnacht M, Johanssen S, Quinkler M, Bucsky P, Willenberg HS, Beuschlein F et al; German Adrenocortical Carcinoma Registry Group; European Network for the Study of Adrenal Tumors. Limited prognostic value of the 2004 International Union Against Cancer staging classification for adrenocortical carcinoma: proposal for a Revised TNM Classification. Cancer. 2009 Jan;115(2):243-50.

26 Ciftci AO, Senocak ME, Tanyel FC, Büyükpamukçu N. Adrenocortical tumors in children. J Pediatr Surg. 2001 Apr;36(4):549-54.

27 Ribeiro RC, Pinto EM, Zambetti GP, Rodriguez-Galindo C. The International Pediatric Adrenocortical Tumor Registry initiative: contributions to clinical, biological, and treatment advances in pediatric adrenocortical tumors. Mol Cell Endocrinol. 2012 Mar;351(1): 37-43.

28 Satge D, Philippe E, Ruppe M, Levy JM, Lutz P, Walter P. Neonatal carcinoma. Review of the literature apropos of a case. Bull Cancer. 1988;75(4):373-84.

29 Saracco S, Abramowsky C, Taylor S, Silverman RA, Berman BW. Spontaneously regressing adrenocortical carcinoma in a newborn. A case report with DNA ploidy analysis. Cancer. 1988 Aug;62(3):507-11.

30 García E, Cordero Gallardo G, Lugo-Vicente $\mathrm{H}$. Adrenocortical carcinoma in a female infant: a case report. Bol Asoc Med P R. 2013; 105(4):52-5.

31 Hishiki T, Kazukawa I, Saito T, Terui K, Mitsunaga T, Nakata $\mathrm{M}$ et al. Diagnosis of adrenocortical tumor in a neonate by detection of elevated blood 17-hydroxyprogesterone measured as a routine neonatal screening for congenital adrenal hyperplasia: a case report. J Pediatr Surg. 2008 Oct;43(10):e19-22.
32 Kakkar N, Vasishta RK, Lamba A, Trehan A, Marwaha RK. Special feature: pathological case of the month. Denouement and discussion: congenital adrenocortical carcinoma. Arch Pediatr Adolesc Med. 2000 Dec;154(12): 1267-8.

33 Godil MA, Atlas MP, Parker RI, Priebe CJ, Zerah MM, Kane P et al. Metastatic congenital adrenocortical carcinoma: a case report with tumor remission at $31 / 2$ years. J Clin Endocrinol Metab. 2000 Nov;85(11):3964-7.

34 Hubertus J, Boxberger N, Redlich A, von Schweinitz D, Vorwerk P. Surgical aspects in the treatment of adrenocortical carcinomas in children: data of the GPOH-MET 97 trial. Klin Padiatr. 2012 Apr;224(3):143-7.

35 Kepes JJ, O’Boynick P, Jones S, Baum D, McMillan J, Adams ME. Adrenal cortical adenoma in the spinal canal of an 8-year-old girl. Am J Surg Pathol. 1990 May;14(5):481-4.

36 Medeiros LJ, Anasti J, Gardner KL, Pass HI, Nieman LK. Virilizing adrenal cortical neoplasm arising ectopically in the thorax. J Clin Endocrinol Metab. 1992 Dec;75(6):1522-5.

37 Else T, Kim AC, Sabolch A, Raymond VM, Kandathil A, Caoili EM et al. Adrenocortical carcinoma. Endocr Rev. 2014 Apr;35(2):282326.

38 Redlich A, Boxberger N, Strugala D, Frühwald MC, Leuschner I, Kropf S et al. Systemic treatment of adrenocortical carcinoma in children: data from the German GPOH-MET 97 trial. Klin Padiatr. 2012 Oct;224(6):36671.

39 Luton JP, Cerdas S, Billaud L, Thomas G, Guilhaume B, Bertagna X et al. Clinical features of adrenocortical carcinoma, prognostic factors, and the effect of mitotane therapy. N Engl J Med. 1990 Apr;322(17):1195-201.

40 Faria AM, Almeida MQ. Differences in the molecular mechanisms of adrenocortical tumorigenesis between children and adults. Mol Cell Endocrinol. 2012 Mar;351(1):52-7.

41 Das S, Sengupta M, Islam N, Roy P, Datta C, Mishra PK et al. Weineke criteria, Ki-67 index and p53 status to study pediatric adrenocortical tumors: is there a correlation? J Pediatr Surg. 2016 Nov;51(11):1795-800.

42 Liou LS, Kay R. Adrenocortical carcinoma in children. Review and recent innovations. Urol Clin North Am. 2000 Aug;27(3):403-21. 